\title{
PALINOFÁCIES E PROCESSOS DEPOSICIONAIS EM SEDIMENTOS DE FUNDO DA LAGOA DOS QUADROS, PLANÍCIE COSTEIRA DO RIO GRANDE DO SUL, BRASIL
}

\section{KARIN ELISE BOHNS MEYER ${ }^{1}$, PAULO ALVES DE SOUZA², MÁRIO RICARDO CWIK³, TAÍSSA RÊGO MENEZES ${ }^{4} \&$ FRANCISCO SEKIGUCHI BUCHMANN ${ }^{5}$}

\begin{abstract}
Resumo Este estudo é baseado na caracterização qualitativa e quantitativa da matéria orgânica particulada (palinomorfos, fitoclastos opacos, fitoclastos não opacos e matéria orgânica amorfa-MOA) e na aplicação de métodos estatísticos de análise em sedimentos de fundo da Lagoa dos Quadros, Planície Costeira do Rio Grande do Sul. Os resultados permitiram a identificação de cinco palinofácies, com significado paleoambiental. A Palinofácies A, com equivalência dos quatro grupos de matéria orgânica particulada, é associada a processos de suspensão gradacional; as Palinofácies B e C representam controle de influxo fluvial, com diferenças percentuais entre os grupos; a Palinofácies D, com predomínio de MOA e fitoclastos opacos, é correlacionada a processos de suspensão e rolamento; processos de suspensão são atribuídos à Palinofácies E, com predomínio de MOA e palinomorfos. Os resultados demonstram o potencial da análise de palinofácies nas interpretações e reconstituições dos ambientais.
\end{abstract}

Palavras-chave: Palinofácies, Palinologia, Quaternário, processos de deposição, Planície Costeira do Rio Grande do Sul.

\begin{abstract}
PALYNOFACIES AND DEPOSICIONAL PROCESS FROM BOTTOM SEDIMENTS OF OUADROS LAKE, RIO GRANDE DO SUL COASTAL PLAIN, BRAZIL This study is based on the qualitative and quantitative characterization of particulate organic matter (palynomorphs, opaque phytoclasts, non-opaque phytoclasts and amorphous organic matter-AOM) and statistic methods of analysis from bottom sediments of Quadros Lake, of Rio Grande do Sul Coastal Plain. These data provided the identification of five palynofacies, with paleoenvironmental significance. Palynofacies A, with equivalent particulate organic matter among the four groups is associated to processes of gradational suspension; Palynofacies B and C represent fluvial influx control, with percentual differences between the groups; Palynofacies D, predominantly comprised of AOM and opaque phytoclasts is correlated to suspension and traction processes; suspension processes are attributed to Palynofacies E, with AOM and palynomorphs predominance. The results have shown the potential of palynofacies analysis through the interpretation and reconstitution of environments.
\end{abstract}

Keywords: Palynofacies, Palynology, Quaternary, depositional processes, Rio Grande do Sul Coastal Plain.

INTRODUÇÃO A caracterização qualitativa e quantitativa da matéria orgânica particulada contida nos sedimentos e nas rochas sedimentares constitui a análise de palinofácies. Esta técnica consiste na identificação dos componentes particulados individuais, na determinação de suas proporções relativas e absolutas, suas dimensões e seu estado de preservação. Dessa forma, distintas palinofácies podem ser caracterizadas tanto verticalmente, tendo em vista o empilhamento sedimentar, quanto horizontalmente, considerando as variações laterais dos ambientes e processos deposicionais.

O conceito de "palinofácies", introduzido por Combaz (1964) e ampliado por Tyson (1995), é definido como "um corpo de rocha sedimentar contendo um conjunto distinto de matéria orgânica palinológica, que reflita condições ambientais específicas ou que possa ser associado com as características das rochas potencialmente geradoras de hidrocarbonetos".

Numa abordagem geral, considerando os trabalhos de definição conceitual (e.g., Traverse 1994, Tyson 1995, Mendonça Filho 1999), a matéria orgânica particulada que resta após o processamento palinológico padrão $(\mathrm{HF}, \mathrm{HCl})$ é referente a três grupos: palinomorfos (esporos, grãos de pólen, algas, zoomorfos, acritarcos e quitinozoários), fitoclastos (bio-estruturados ou não bioestruturados) e matéria orgânica amorfa (MOA).

A caracterização desses componentes contribui para o en- tendimento dos processos ambientais que controlam a produção da matéria orgânica na biosfera, sua dispersão e deposição nos diferentes ambientes deposicionais, bem como dos fatores físicos e biogeoquímicos que atuam durante a sua incorporação na geosfera (Tyson 1995).

Embora seja uma abordagem utilizada para o Quaternário brasileiro (e.g., Mendonça Filho et al. 2001a, 2001b, 2003), as publicações sobre o tema não oferecem informações detalhadas e completas. Alguns destes trabalhos relacionam a matéria orgânica particulada caracterizada com dados geoquímicos de carbono orgânico total (COT), índice de hidrogênio (IH) e o tipo de matéria orgânica particulada associada que é influenciada pelas condições ambientais.

A aplicação de métodos estatísticos, realizada por Menezes \& Mendonça Filho (2004), com a utilização de análises de agrupamento (modo- $Q$ e modo- $R$ ), permitiu a caracterização de palinofácies e suas correlações com os parâmetros hidrodinâmicos e eventos geológicos para o Pleistoceno da Bacia de Campos. Dessa forma, os autores demonstraram a importância do tratamento estatístico como método auxiliar na definição das palinofácies.

O principal objetivo deste trabalho é a caracterização da matéria orgânica particulada contida em amostras de fundo da Lagoa dos Quadros, seguindo-se a análise dos parâmetros sedi-

1-CPMTC/IGC, Universidade Federal de Minas Gerais. Av. Antônio Carlos 6.627, 31.270-901, Belo Horizonte, MG, Brasil. bohnsmeyer@yahoo.com.br 2-Laboratório de Palinologia, Instituto de Geociências, Universidade Federal do Rio Grande do Sul. Av. Bento Gonçalves, 9500, 91540-000, Porto Alegre, RS, Brasil.paulo.alves.souza@ufrgs.br

3-PETROBRAS/ENGENHARIA/EPTM/EDI. EDHIB. Rua General Canabarro 500, Rio de Janeiro, RJ. mr.cwik@petrobras.com.br

4-PETROBRAS/CENPES/DIVEX/CEGEQ. Cidade Universitária, Quadra 7, Ilha do Fundão, Rio de Janeiro. taissamenezes@petrobras.com.br 5-Universidade Estadual Paulista -UNESP, Campus do Litoral Paulista, Campus São Vicente. Praça Infante D. Henrique, s/no, 11330-900. São Vicente, SP, Brasil. buchmann@csv.unesp.br 
mentológicos e hidrodinâmicos do sistema e o estabelecimento de correlação das palinofácies identificadas com os processos de sedimentação caracterizados para a lagoa. A análise de palinofácies integrada aos processos sedimentares sub-recentes ou recentes é de fundamental importância nas Geociências, por oferecer parâmetros para as reconstituições ambientais de depósitos antigos.

CONTEXTO ESTRATIGRÁFICO REGIONAL A Bacia de Pelotas ocupa uma área de $70.000 \mathrm{~km}^{2}$, estendendo-se desde o sul da Plataforma de Florianópolis até o lineamento de Chuí (Ghignone 1960). A origem da bacia está relacionada aos eventos tectônicos ocorridos durante o EoCretáceo que provocaram a abertura do Oceano Atlântico Sul. Seus depósitos cobrem o embasamento, constituído pelo complexo cristalino pré-cambriano, e seqüências sedimentares e vulcânicas paleozóicas e mesozóicas da Bacia do Paraná.

A Planície Costeira do Rio Grande do Sul é uma área de terras baixas com cerca de $33.000 \mathrm{~km}^{2}$, correspondente à região de exposição dos depósitos mais superficiais e proximais da seqüência sedimentar acumulada na Bacia de Pelotas (Tomazzelli \& Villwock 2000).

Durante o Quaternário, esta planície costeira esteve sujeita ao desenvolvimento de um amplo sistema de leques aluviais, na parte mais interna, e ao acréscimo de quatro sistemas deposicionais do tipo laguna-barreira, denominados, sistemas laguna-barreira I, II, III e IV (Villwock 1984, Villwock \& Tomazelli 1995, Tomazelli \& Villwock 2000).

A Lagoa dos Quadros está situada no município de Capão da Canoa, entre as coordenadas geográficas $29^{\circ} 38^{\prime} 08^{\prime \prime}-29^{\circ} 46^{\prime} 07^{\prime \prime} \mathrm{S}$ e $50^{\circ} 01$ ' 14 " $-50^{\circ} 08^{\prime} 56^{\prime \prime}$ W (Figura 1). Sua evolução está relacionada ao contexto do sistema laguna-barreira IV de Villwock (1986), Villwock \& Tomazelli (1995) e Tomazelli \& Villwock (2000). O sistema laguna barreira IV é o mais recente dos quatro sistemas, tendo evoluído durante o Holoceno e está associado à Última Transgressão Marinha holocênica.

ASPECTOS FÍSICOS E SEDIMENTOLÓGICOS A Lagoa dos Quadros é a segunda maior lagoa do litoral norte do Rio Grande do Sul, com 121, $26 \mathrm{~km}^{2}$ de área e $355.480 .315 \mathrm{~m}^{3}$ em capacidade de volume d'água, profundidade média de 3,00 $\mathrm{m}$, com suave caimento para leste $(3,90 \mathrm{~m})$, configurando uma assimetria no piso lagunar. Os aspectos físicos e sedimentológicos da lagoa foram estudados, em detalhe, por Cwik (1999),

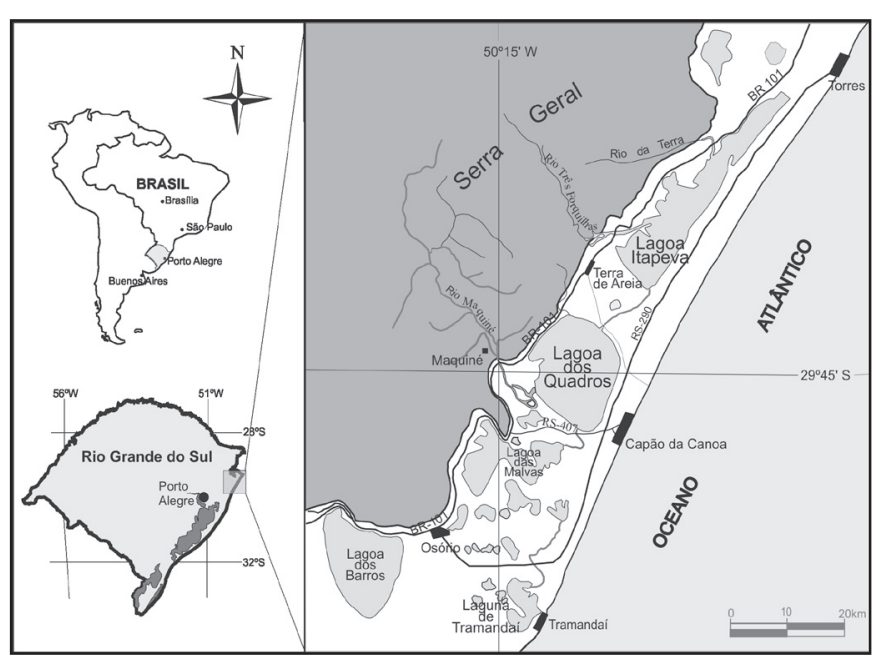

Figura 1. Mapa de localização da Lagoa dos Quadros, Planície Costeira Norte do Rio Grande do Sul, Brasil. conforme sinteticamente apresentados a seguir.

Os principais aportes sedimentares de origem fluvial são oriundos do Rio Maquiné e do Arroio Sanga Funda, predominando o material de granulometria areia muito fina a silte. As altas precipitações que ocorrem no planalto condicionam o volume d'água das drenagens e a quantidade de material trazido para o interior da lagoa. A região deltaica junto à desembocadura do Rio Maquiné favorece a deposição dos sedimentos mais grossos (areia média e fina) transportados pelo rio, enquanto que o material fino (siltes e argilas) é transportado em suspensão.

Os sedimentos do fundo lacustre foram separados, com base na granulometria, em quatro fácies sedimentares: fácies arenosa, fácies areno-síltica, fácies síltico-arenosa e fácies síltica (Figura 2).

Os sedimentos das fácies arenosas apresentam propriedades semelhantes aos depositados em ambiente praial e eólico, compostos por duas populações: uma de grãos bem arredondados e foscos, característicos de dunas litorâneas, e outra de grãos subarredondados e polidos de planície praial. As características texturais destes sedimentos são indicativas de ambientes de alta energia, atuantes anteriormente ao estabelecimento da lagoa.

Os sedimentos das fácies sílticas estão condicionados às regiões abrigadas da ação dos ventos e nas maiores profundidades, onde a energia cinética menor favorece sua deposição. As ondas acionadas pelos ventos constantes ao longo do ano mantém o material fino (argilas) em suspensão, não ocorrendo depósitos significativos de fundo. O registro de sedimentos finos em profundidades próximas a $3,00 \mathrm{~m}$ indica que a velocidade orbital das ondas não é efetiva nesta profundidade, permitindo a depo-

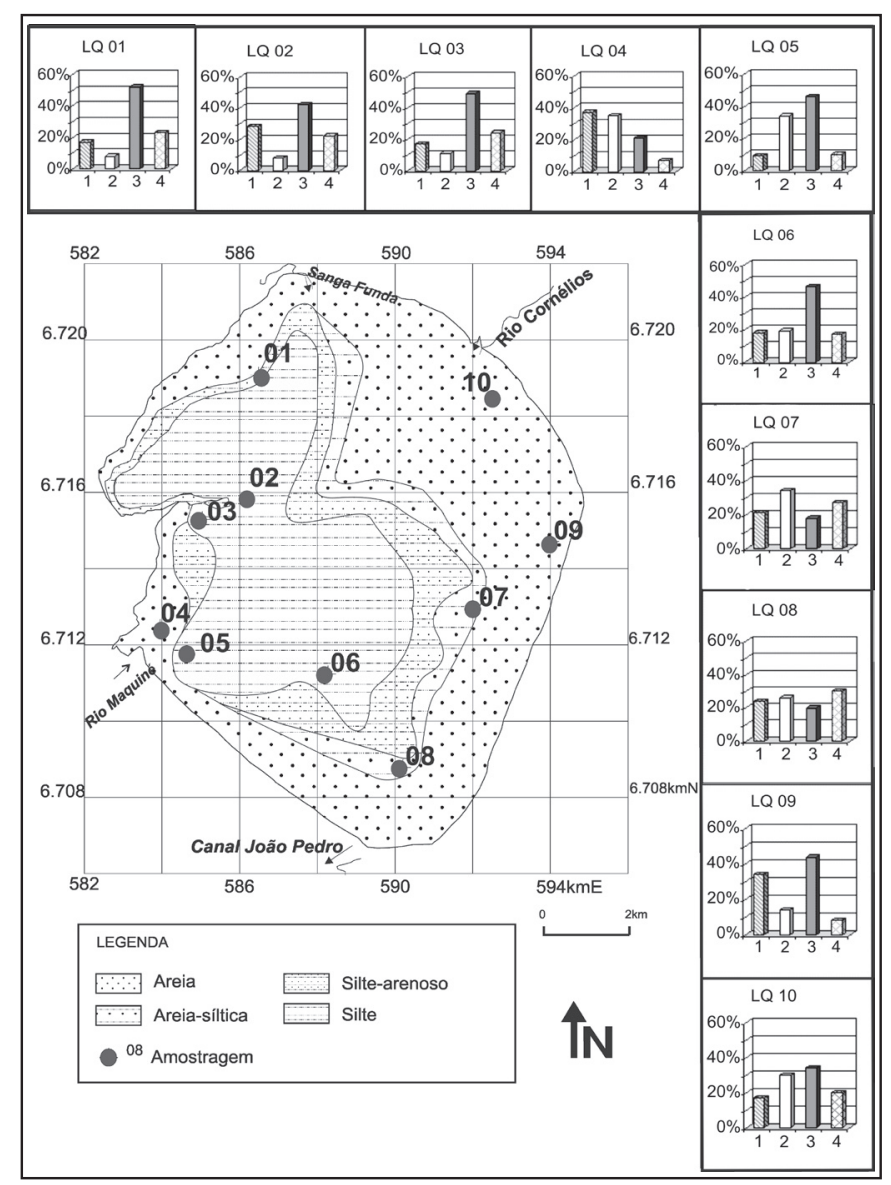

Figura 2. Mapa textural dos sedimentos de fundo, localização dos pontos de amostragem e distribuição dos principais grupos da matéria orgânica particulada (modificado de Cwik 1999). 
sição. Na região central, os sedimentos apresentam assimetrias positivas a muito positivas, características de baixa energia.

Os fatores que controlam a circulação das águas na Lagoa dos Quadros são os ventos, através das ondas, e as correntes fluviais. A atuação destes fatores hidrodinâmicos (Figura 3), associados à morfologia do corpo lacustre, exerce um importante controle sobre a distribuição faciológica dos sedimentos de fundo. A suspensão e a saltação foram os principais processos de transporte identificados para os sedimentos de fundo na lagoa.

MATERIAL E MÉTODOS Foram realizados dez testemunhos em tubos de PVC com $10 \mathrm{~cm}$ de diâmetro e $70 \mathrm{~cm}$ de comprimento em dez pontos do fundo lacustre visando à amostragem de diferentes tipos de sedimentos (Figura 2). As amostras superficiais (LQ-01 a LQ-10) de cada um dos testemunhos (2 $\mathrm{cm}^{3}-10 \mathrm{~g}$ sedimento cada) foram coletadas para as análises de palinofácies e palinológica.

O tratamento químico das amostras foi realizado no Laboratório de Palinologia da Universidade Luterana do Brasil (ULBRA), de acordo com os procedimentos palinológicos não-oxidativos descritos por Tyson (1995) e Mendonça Filho (1999), que consistem, basicamente, no tratamento com ácido clorídrico e fluorídrico para eliminação da fração mineral e na separação e concentração da matéria orgânica do resíduo mineral com cloreto de zinco.

A fração maior que $6 \mu \mathrm{m}$ foi concentrada para a montagem de lâminas em meio de gelatina glicerinada. As lâminas estão depositadas na Palinoteca do Museu de Paleontologia do Departamento de Paleontologia e Estratigrafia do Instituto de Geociências da UFRGS sob a numeração MP-P 5001 a 5010.

$\mathrm{O}$ estudo de palinofácies consistiu da análise qualitativa e quantitativa dos diferentes componentes da matéria orgânica particulada (Figura 4), baseada no sistema de classificação proposto por Tyson (1995), com adaptações introduzidas.

A classificação da matéria orgânica particulada foi feita em microscopia de luz branca transmitida sob aumentos de 250 e 400 x. A intensidade relativa da fluorescência dos componentes da matéria orgânica foi medida com o uso de luz azul refletida no microscópio Olympus BX-51 do Laboratório de Palinologia do Departamento de Paleontologia e Estratigrafia do IG da UFRGS.

Duas contagens foram realizadas, a primeira de palinofácies, considerando toda a matéria orgânica particulada até 300 partículas; a segunda visando à determinação da freqüência relativa dos táxons reconhecidos no conjunto de palinomorfos.

$\mathrm{O}$ tratamento estatístico consistiu em análises de agrupamento modo- $Q$ e modo- $R$, realizadas a partir dos percentuais relativos dos componentes da matéria orgânica particulada. Ambos os métodos contemplam a reunião, em agrupamentos, de diferentes tipos de matéria orgânica particulada. O coeficiente de correlação linear de Pearson ( $r$-Pearson) foi empregado para quantificar a dependência linear entre os elementos e, assim, determinar a matriz de correlação, pela qual valores mais próximos a +1 correspondem ao maior grau de correlação, enquanto que os valores próximos de -1 apontam um menor grau de correlação entre as amostras (Valentin, 2000).

\section{RESULTADOS}

Caracterização e distribuição dos grupos da matéria orgânica particulada Os resultados da distribuição quantitativa e da análise qualitativa dos grupos da matéria orgânica particulada nas amostras estudadas estão sintetizados nas Figuras 2 e 4. Os fitoclastos foram divididos em não opacos (de coloração amarela escura a marrom) e opacos (de coloração preta inclusive nas porções marginais da partícula). Os fitoclastos não opacos e opacos foram subdivididos em categorias de acordo com sua morfologia, presença ou ausência de elementos estruturais e seu estado de preservação. O primeiro grupo dos fitoclastos está representado por fitoclastos não opacos bioestruturados estriados, cutículas e fitoclastos não opacos não bioestruturados. Os fitoclastos não opacos bioestruturados estriados, dominantes nas amostras LQ-07, LQ-05, LQ-04 e LQ-10, derivados de tecidos de vegetais superiores, quando observados em luz branca transmitida apresentam coloração que varia de marrom claro a médio, com contornos angulares a levemente corroídos.

As cutículas, que são fragmentos da epiderme de folhas de vegetais superiores, apresentam coloração amarelo-pálido ao marrom-claro, com excelente preservação das estruturas celulares características das epidermes. Em geral, as cutículas se apresentam não-degradadas, com contornos nítidos.

Os fitoclastos não opacos não bioestruturados são partículas que não possuem estrutura botânica interna, de coloração marrom-claro, equidimensionais quanto à forma, com contornos nítidos ou levemente irregulares e lascados. Sua maior distribuição foi verificada nas amostras LQ-08, LQ-04 e LQ-10.

No grupo dos fitoclastos opacos foi constatado o predomínio de fitoclastos opacos corroídos, de forma irregular e degradada, em relação aos alongados e bio-estruturados. As maiores concentrações destas partículas foram registradas nas amostras LQ04 e LQ-09, de granulometria areia.

A MOA dos sedimentos de fundo é representada por matéria orgânica não estruturada com forma e contorno irregulares, de matriz granular e heterogênea. Ocorre sob a forma de grumos ou dispersa, com diferentes tonalidades de marrom quando analisada sob microscopia óptica. A análise quantitativa mostrou que a MOA é o grupo mais significativo em seis das dez amostras estudadas, sendo cinco destas amostras relacionadas à granulometria silte e silte-arenoso e uma relacionada à granulometria areia.

$\mathrm{Na}$ análise de palinofácies, os palinomorfos foram divididos em esporomorfos de origem terrestre (grãos de pólen e esporos) microplâncton de parede orgânica (algas) e zoomorfos (ovos de platelmintos). Dentre os esporomorfos, é significativa a distribuição de esporos em relação aos grãos de pólen. Os esporos monoletes ornamentados e não-ornamentados têm maior distribuição nas amostras LQ-01 de granulometria silte-arenosa, LQ-02, LQ-03 e LQ-06 de granulometria siltosa e LQ-07 de granulometria areia-síltica.

Fluorescência Os esporos e grãos de pólen apresentaram fluorescência amarelo-intensa, porém, menos intensa que a das algas, como Botryococcus Kützig 1849 e Pediastrum, Meyen 1929 de fluorescência amarelo-esverdeada. A MOA apresentou uma fluorescência nos níveis 2 e 3 de acordo com a escala de Tyson (1995). Os fitoclastos não opacos apresentaram a fluorescência mais fraca, variando do amarelo-escuro ao laranja, enquanto que as cutículas apresentaram fluorescência amareloclaro. Os fitoclastos opacos não apresentaram fluorescência.

Análise de agrupamento modo-R e r-Pearson $\mathrm{O}$ dendograma obtido da análise de agrupamento modo- $R$ (Figura 5) permitiu a separação de sete agrupamentos formados pelos diferentes componentes da matéria orgânica particulada. A partir da análise da matriz de correlação $r$-Pearson foram estabelecidas similaridades entre os diferentes componentes da matéria orgânica particulada. Dessa forma na Tabela 1 estão listados os principais componentes de cada agrupamento com correspondência de equivalência hidrodinâmica.

Análise de agrupamento modo- $\boldsymbol{Q}$ O dendograma produzido a partir da análise de agrupamento pelo modo- $Q$ (Figura 6) indica cinco agrupamentos, correspondentes a cinco palinofácies, cujas características estão sintetizadas na Tabela 2. Os valores expressos em porcentagem refletem a média de cada componen- 
te de matéria orgânica particulada nas amostras.

Caracterização das palinofácies Palinofácies A (amostras LQ-07 e LQ-08): A análise do modo- $Q$ confirma uma certa distribuição proporcional entre os grupos dos componentes da

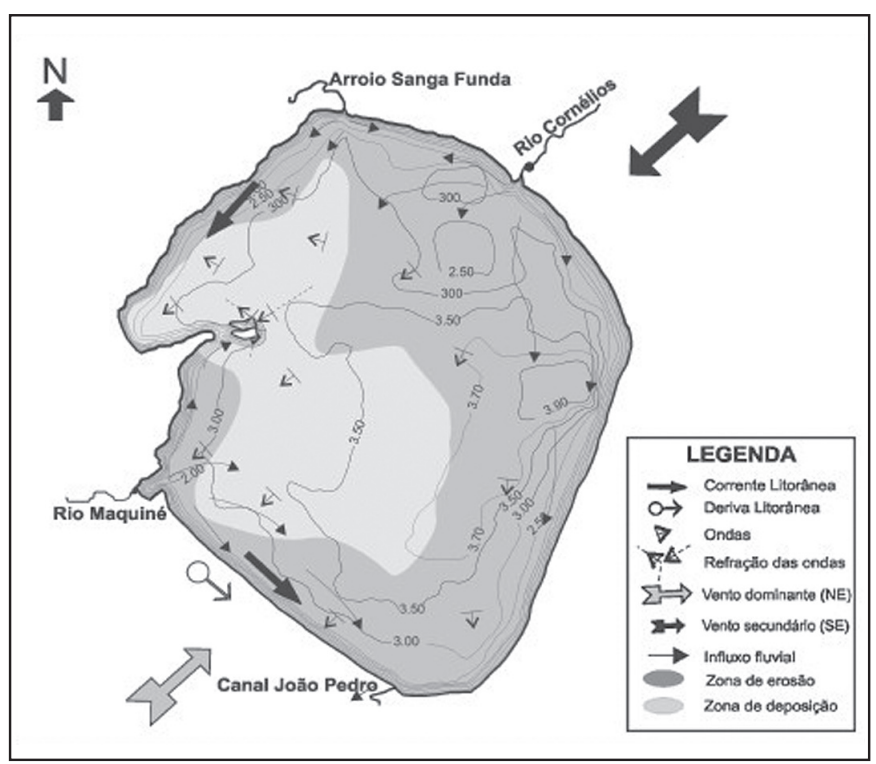

Figura 3. Condições hidrodinâmicas atuantes na Lagoa dos Quadros (modificado de Cwik 1999). matéria orgânica particulada considerados para ambas as amostras (Tabela 2), que são referentes a uma mesma granulometria (areia-síltica). Em termos de processos deposicionais, Cwik (1999) interpretou as amostras como relacionadas ao processo de suspensão gradacional, que consiste na deposição de sedimentos pelo decréscimo gradual do tamanho e concentração dos grãos de sedimento, do topo em direção ao fundo da coluna em suspensão. No processo deposicional de suspensão gradacional as partículas são jogadas para o alto pela corrente de turbulência de fundo, sendo a seleção do depósito, neste processo deposicional, feita fora desta corrente de fundo (Tabela 3 ).

Palinofácies B (amostra LQ-04): O predomínio de fitoclastos opacos e não opacos caracteriza esta palinofácies, que é associada à granulometria areia e ao processo deposição em suspensão e rolamento (Cwik 1999) onde ocorre mistura de grãos rolados e sedimentos em suspensão. Os grãos rolados têm velocidade mais baixa que a corrente e são desviados por suspensão (Tabela 3).

Palinofácies C (amostras LQ-05 e LQ-10): Esta palinofácies se caracteriza pelo predomínio de MOA e fitoclastos não opacos em ambas as amostras. No entanto, as amostras diferem quanto à granulometria e ao processo de deposição, sendo a amostra LQ-05 corresponde à granulometria silte, depositada em processo de suspensão em águas calmas (Cwik 1999), e a amostra LQ-10 referente à granulometria areia, depositada por processo de suspensão e rolamento.

Palinofácies D (amostras LQ-02 e LQ-09): A MOA e os fitoclastos opacos foram os grupos de matéria orgânica particulada com maior distribuição em ambas amostras desta palinofácies. No entanto, a porcentagem de palinomorfos foi maior na amostra LQ-02. As amostras também diferem quanto à granulometria

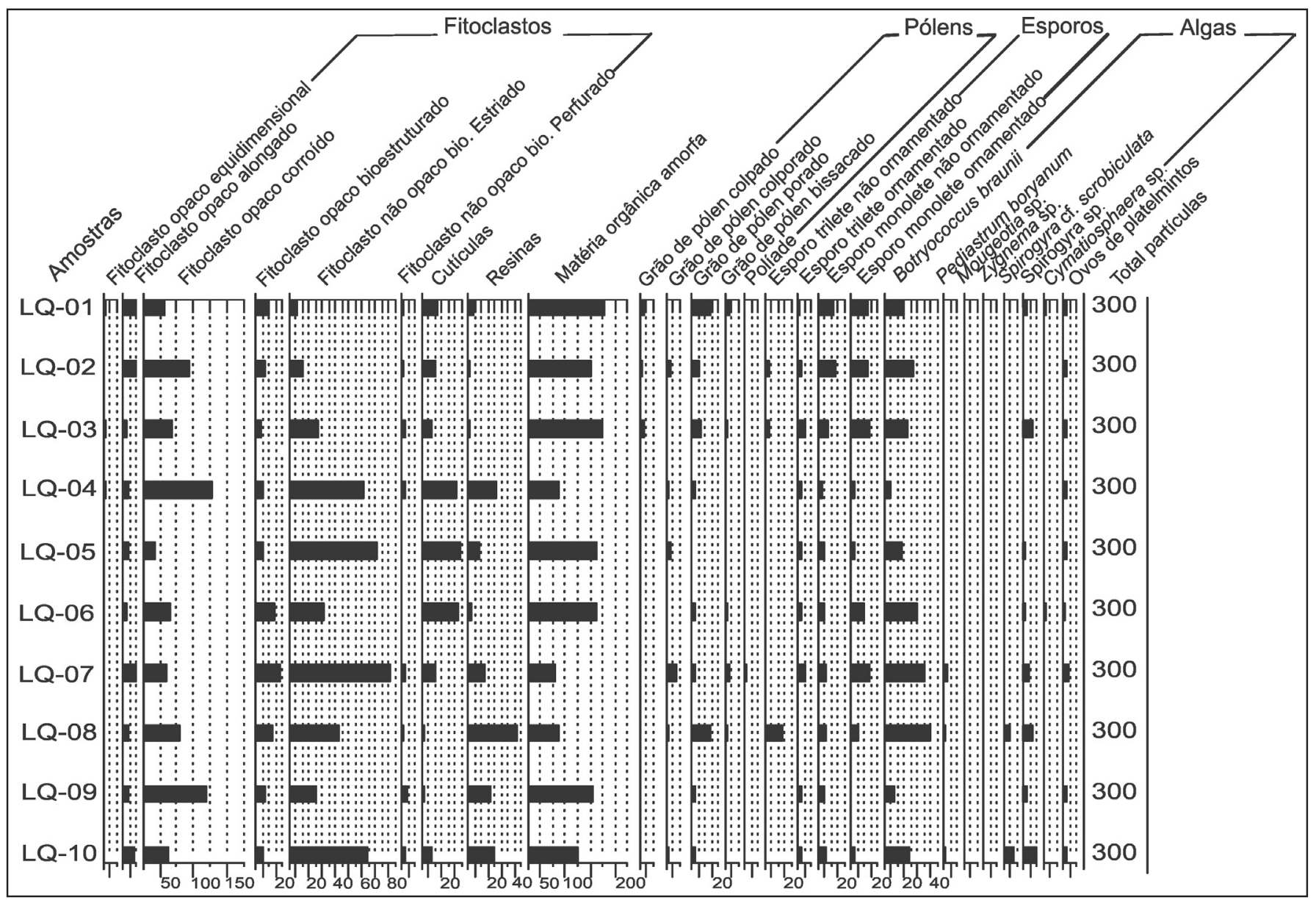

Figura 4. Freqüência absoluta dos componentes da matéria orgânica particulada por amostra. 


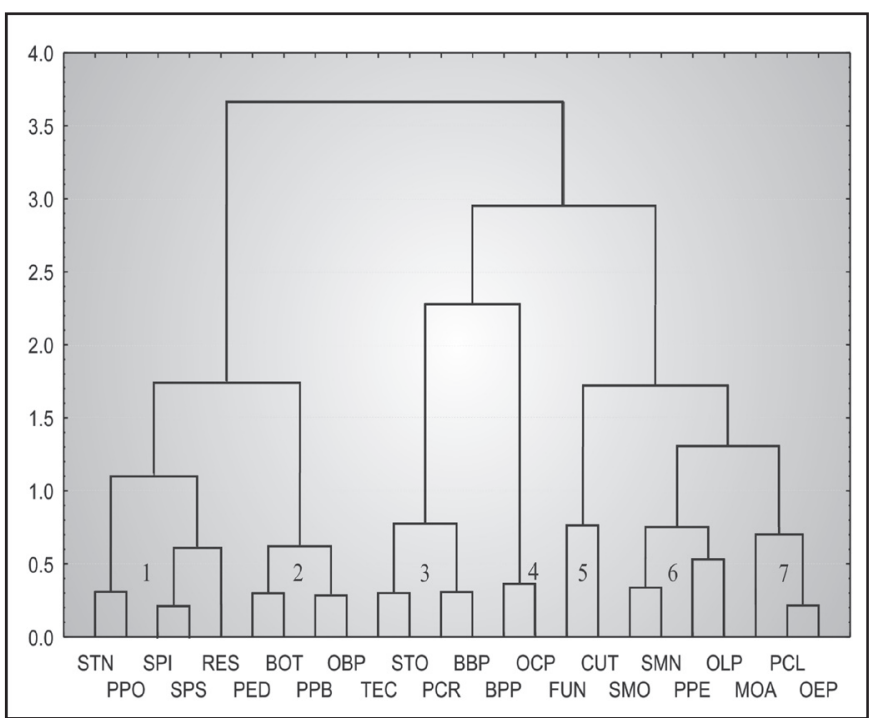

Figura 5. Dendograma obtido a partir da análise de agrupamento modo- $R$ para os componentes da matéria orgânica particulada (STN: esporo trilete não-ornamentado;PPO: grão de pólen porado; SPI: Spirogyra sp.; SPS: Spirogyra cf. scrobiculata;RES: resinas; PED: Pediastrum boryanum; BOT: Botryococus braunii; PPB: grão de pólen bissacado; OBP: fitoclasto opaco bioestruturado; TEC: tecamebas; STO: esporo trilete ornamentado; PCR: grão de pólen colporado; BBP: $f$ toclasto não opaco bioestruturado; BPP: fitoclasto não opaco bioestruturado perfurado; OCP: fitoclasto opaco corroído; estriado; FUN: esporos de fungo; CUT: cutícula; SMO: esporo monolete ornamentado; SMN: esporo monolete não-ornamentado; PPE: ovos de platelmintos; OLP: fitoclasto opaco alongado; MOA: matéria orgânica amorfa;PCL: grão de pólen colpado;OEP: fitoclasto opaco equidimensional.

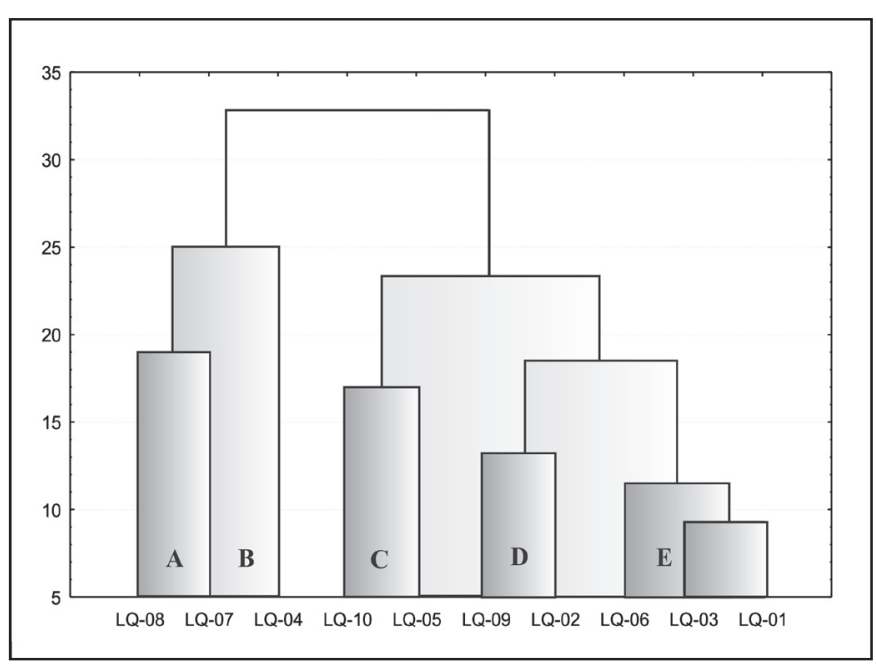

Figura 6. Dendograma obtido da análise de agrupamento modo-Q para os componentes da matéria orgânica particulada ( $A, B, C, D$ e E correspondem as palinofácies identificadas).

e ao processo de deposição. A amostra LQ-02, de granulometria silte, foi depositada por processo de suspensão em águas calmas, enquanto que a amostra LQ-09 corresponde a areia depositada em processo de suspensão e rolamento (Cwik 1999).

Palinofácies E (amostras LQ-01, LQ-03 e LQ-06): Esta palinofácies apresenta o predomínio de MOA e distribuição dos
Tabela 1. Agrupamentos dos componentes da matéria orgânica particulada com base na análise de cluster (modo-R e r-Pearson), indicando equivalência hidrodinâmica entre os componentes.

\begin{tabular}{c|l}
\hline GRUPOS & $\begin{array}{l}\text { Componentes da matéria orgânica parti- } \\
\text { culada com equivalência hidrodinâmica }\end{array}$ \\
\hline $\mathbf{1}$ & $\begin{array}{l}\text { Esporos triletes não-ornamentados } \\
\text { Grãos de pólen porados } \\
\text { Spirogyra Link 1820 (Spirogyra cf. scrobi- } \\
\text { culata e } S \text {. sp.) } \\
\text { Resinas }\end{array}$ \\
\hline $\mathbf{2}$ & $\begin{array}{l}\text { Pediastrum boryanun Meyen 1829 } \\
\text { Botryococcus braunii Kützig 1849 } \\
\text { Grãos de pólen bissacados } \\
\text { Fitoclastos opacos bioestruturados }\end{array}$ \\
\hline $\mathbf{4}$ & $\begin{array}{l}\text { Esporos triletes ornamentados } \\
\text { Grãos de pólen colporados } \\
\text { Fitoclastos não opacos bioestruturados es- } \\
\text { triados }\end{array}$ \\
\hline $\mathbf{5}$ & $\begin{array}{l}\text { Fitoclastos não opacos bioestruturados per- } \\
\text { furados } \\
\text { Fitoclastos opacos corroídos }\end{array}$ \\
\hline Cutículas \\
Esporos de fungos
\end{tabular}

demais componentes da matéria orgânica particulada com similaridades, sendo que a amostra LQ-06 apresentou proporções iguais de fitoclastos opacos e não opacos. Em termos de correspondência granulométrica, há correlação entre as amostras sílticas LQ-06 e LQ-03, atribuídas a processos de suspensão em águas calmas, enquanto que a amostra LQ-01, síltico-arenosa, é atribuída a processo de suspensão uniforme, que se caracteriza por uma pluma de suspensão de partículas não selecionadas pelas correntes de fundo, com constância vertical em concentração e tamanhos dos grãos (Cwik 1999).

DISCUSSÃO A matéria orgânica particulada recuperada dos diferentes sedimentos de fundo da Lagoa dos Quadros reflete um sistema complexo que envolve a dispersão e a sedimentação da matéria orgânica controladas por processos de deposição e por condições hidrodinâmicas geradas a partir da configuração da lagoa, da faciologia sedimentar, do regime de ventos e dos sistemas fluviais.

A maior distribuição de fitoclastos não opacos (bioestruturados estriados, cutículas e não opacos não bioestruturados) nas amostras próximas ao influxo fluvial dos rios Maquiné e Cornélios mostra uma tendência já conhecida em palinofácies: de maior distribuição destas partículas em sedimentos relacionados a fontes fluviais (e.g., Tyson 1993, Trigüis \& Araújo 2001, Men- 
Tabela 2. Palinofácies identificadas. * MOA: matéria orgânica amorfa, OP: fitoclastos opacos; NOP: fitoclastos não opacos; PAL: palinomorfos.

\begin{tabular}{c|c|c|c|c|c}
\hline $\begin{array}{c}\text { Palinofácies } \\
\text { (amostras) }\end{array}$ & $\begin{array}{c}\text { Granulometria } \\
\text { Profundidade }(\mathbf{m})\end{array}$ & MOA & OP & NOP & PAL \\
\hline $\begin{array}{c}\mathbf{A} \\
(\mathrm{LQ}-07 \mathrm{e} \text { LQ-08) }\end{array}$ & $\begin{array}{c}\text { Areia síltica } \\
(3,70-3,00)\end{array}$ & $20 \%$ & $22 \%$ & $30 \%$ & $28 \%$ \\
\hline $\begin{array}{c}\mathbf{B} \\
(\mathrm{LQ}-04)\end{array}$ & $\begin{array}{c}\text { Areia } \\
(2,50)\end{array}$ & $21 \%$ & $37 \%$ & $35 \%$ & $7 \%$ \\
\hline $\begin{array}{c}\mathbf{C} \\
(\mathrm{LQ}-05 \text { e LQ-10) }\end{array}$ & $\begin{array}{c}\text { Areia e Silte } \\
(2,50)\end{array}$ & $40 \%$ & $12 \%$ & $32 \%$ & $16 \%$ \\
\hline $\begin{array}{c}\mathbf{D} \\
(\mathrm{LQ}-02 \text { e LQ-09) }\end{array}$ & $\begin{array}{c}\text { Silte e areia } \\
(3,00 ; 3,70)\end{array}$ & $43 \%$ & $31 \%$ & $11 \%$ & $15 \%$ \\
\hline $\begin{array}{c}\mathbf{E} \\
(\mathrm{LQ}-01, \mathrm{LQ}-03 \mathrm{e} \\
\mathrm{LQ}-06)\end{array}$ & $\begin{array}{c}\text { Silte e silte arenoso } \\
(3,50 ; 2,50 ; 3,00)\end{array}$ & $49 \%$ & $17 \%$ & $13 \%$ & $21 \%$ \\
\hline
\end{tabular}

Tabela 3. Informações sobre as amostras estudadas, principais fatores hidrodinâmicos e processos deposicionais na Lagoa dos Quadros (modificado de Cwik 1999).

\begin{tabular}{|c|c|c|c|}
\hline $\begin{array}{c}\text { AMOSTRA } \\
\text { GRANULOMETRIA }\end{array}$ & $\begin{array}{l}\text { PROF. } \\
\text { (m) }\end{array}$ & HIDRODINÂMICA & PROCESSO DEPOSICIONAL \\
\hline $\begin{array}{c}\text { LQ-01 } \\
\text { Silte-arenoso }\end{array}$ & 3,00 & $\begin{array}{l}\text { Interface zona de } \\
\text { erosão/deposição } \\
\text { Influxo do Arroio } \\
\text { Sanga Funda }\end{array}$ & $\begin{array}{l}\text { Suspensão uniforme } \\
\text { Coluna de suspensão formada de partículas não selecionadas } \\
\text { pelas correntes de fundo, constância vertical em concentração } \\
\text { e tamanho dos grãos. }\end{array}$ \\
\hline $\begin{array}{l}\text { LQ-02 } \\
\text { Silte }\end{array}$ & 3,00 & Zona de deposição & $\begin{array}{c}\text { Suspensão em águas calmas } \\
\text { Baixa energia cinética favorecendo a sedimentação. }\end{array}$ \\
\hline $\begin{array}{l}\text { LQ-03 } \\
\text { Silte }\end{array}$ & 2,50 & $\begin{array}{l}\text { Zona de deposição } \\
\text { Influxo do Rio } \\
\text { Maquiné }\end{array}$ & $\begin{array}{l}\text { Suspensão em águas calmas } \\
\text { Baixa energia cinética favorecendo a sedimentação. }\end{array}$ \\
\hline $\begin{array}{c}\text { LQ-04 } \\
\text { Areia }\end{array}$ & 2,50 & $\begin{array}{l}\text { Zona de erosão } \\
\text { Influxo do Rio } \\
\text { Maquiné }\end{array}$ & $\begin{array}{l}\text { Suspensão e rolamento } \\
\text { Mistura de grãos rolados e sedimentos em suspensão; os } \\
\text { grãos rolados têm velocidade mais baixa e são desviados pela } \\
\text { suspensão. }\end{array}$ \\
\hline $\begin{array}{l}\text { LQ-05 } \\
\text { Silte }\end{array}$ & 2,50 & $\begin{array}{l}\text { Zona de deposição } \\
\text { Influxo do Rio } \\
\text { Maquiné }\end{array}$ & $\begin{array}{c}\text { Suspensão em águas calmas } \\
\text { Baixa energia cinética favorecendo a sedimentação. }\end{array}$ \\
\hline $\begin{array}{l}\text { LQ-06 } \\
\text { Silte }\end{array}$ & 3,50 & Zona de deposição & $\begin{array}{c}\text { Suspensão em águas calmas } \\
\text { Baixa energia cinética favorecendo sedimentação. }\end{array}$ \\
\hline $\begin{array}{c}\text { LQ-07 } \\
\text { Areia-síltica }\end{array}$ & 3,70 & $\begin{array}{l}\text { Interface zona de } \\
\text { erosão/deposição } \\
\text { Influxo do Rio } \\
\text { Cornélios }\end{array}$ & $\begin{array}{l}\text { Suspensão gradacional } \\
\text { Decréscimo gradual em tamanho e concentração dos grãos de } \\
\text { sedimento; as partículas são removidas para alto pela corrente } \\
\text { de turbulência; a seleção do depósito e feita fora da corrente } \\
\text { de fundo. }\end{array}$ \\
\hline $\begin{array}{c}\text { LQ-08 } \\
\text { Areia-síltica }\end{array}$ & 3,00 & $\begin{array}{l}\text { Interface zona de } \\
\text { erosão/deposição } \\
\text { Limite influxo dos } \\
\text { rios Maquiné } \\
\text { e Cornélios }\end{array}$ & $\begin{array}{l}\text { Suspensão gradacional } \\
\text { Decréscimo gradual em tamanho e concentração dos grãos } \\
\text { de sedimento; as partículas são removidas para o alto pela } \\
\text { corrente de turbulência; a seleção do depósito é feita fora da } \\
\text { corrente de fundo. }\end{array}$ \\
\hline $\begin{array}{l}\text { LQ-09 } \\
\text { Areia }\end{array}$ & 3,70 & $\begin{array}{l}\text { Zona de erosão } \\
\text { Influxo do Rio } \\
\text { Cornélios }\end{array}$ & $\begin{array}{l}\text { Suspensão e rolamento } \\
\text { Mistura de grãos rolados e sedimentos em suspensão; os } \\
\text { grãos rolados têm velocidade mais baixa e são desviados pela } \\
\text { suspensão. }\end{array}$ \\
\hline $\begin{array}{l}\text { LQ-10 } \\
\text { Areia }\end{array}$ & 2,50 & $\begin{array}{l}\text { Zona de erosão } \\
\text { Influxo do Rio } \\
\text { Cornélios }\end{array}$ & $\begin{array}{l}\text { Suspensão e rolamento } \\
\text { Mistura de grãos rolados e sedimentos em suspensão; os } \\
\text { grãos rolados têm velocidade mais baixa e são desviados pela } \\
\text { suspensão. }\end{array}$ \\
\hline
\end{tabular}


donça Filho et al. 2001a).

$\mathrm{O}$ registro de cutículas nas amostras estudadas reflete sua alta capacidade de flutuação uma vez que apresenta distribuição equivalente para amostras proximais (LQ-04, suspensão e rolamento) e amostras mais distais (LQ-05 e LQ-06) depositadas por processos de suspensão em águas calmas. Fragmentos relativamente grandes de cutículas e mesmo folhas inteiras, característicos de fácies de prodelta, são freqüentemente encontrados no topo de embaiamento de deltas e fácies distributárias, características de fácies de condições de baixa energia, onde o aporte ocorre por flutuação ou suspensão (Trigüis \& Araújo, 2001).

A maior concentração de fitoclastos opacos, relacionada a amostras de granulometria areia (amostras LQ-04 e LQ-09) e a processos de deposição sob influência das correntes, reflete a característica refratária destas partículas e sua maior resistência à degradação e ao transporte. O predomínio de fitoclastos opacos corroídos em relação aos alongados e bioestruturados reflete a origem proximal dos sedimentos destas amostras, já que fitoclastos opacos alongados, por serem mais flutuantes, podem ser transportados a longas distâncias e depositados em fácies mais distais (e.g., Tyson 1995, Courtinat et al. 2003).

De acordo com Cwik (1999), o processo de transporte sedimentar mais importante na Lagoa dos Quadros se dá por suspensão, seguido pelo processo de saltação. $\mathrm{O}$ registro significativo da MOA em seis das dez amostras estudadas reflete o processo de suspensão. A abundância relativa e absoluta de MOA nas amostras de granulometria silte e síltico-arenosa confirma uma tendência observada nos estudos de palinofácies, na qual a maior preservação de MOA é predominante em sedimentos finos em áreas de baixa oxigenação de fundo, constituindo ambientes anóxicos a desóxicos (e.g., Tyson 1995, Trigüis \& Araújo 2001, Mendonça Filho et al. 2003) e na interface da zona de erosão e deposição (amostras LQ-01, LQ-07 e LQ-09). O percentual elevado de MOA na amostra LQ-09, deve estar relacionado à população de areia fina no conjunto areia que, na margem leste da lagoa, tem contribuição do processo de suspensão na deposição (Cwik 1999, p. 132).

Outro fator importante na preservação da MOA são as condições desóxicas-anóxicas. Nos sedimentos de fundo da Baía de Guanabara, no Rio de Janeiro, estudados por Mendonça Filho et al. (2003), o alto grau de preservação de MOA sugere que a maior parte das amostras de fundo da Baía de Guanabara foi depositada em ambiente desóxico-anóxico, com intensa atividade microbiológica.

Dentre os palinomorfos de origem terrestre, a ocorrência significativa de esporos em relação aos grãos de pólen reflete o aporte fluvial como principal mecanismo de transporte desde as áreas fonte da vegetação. Os esporos monoletes ornamentados e não-ornamentados apresentaram boa distribuição em fácies distais (amostras LQ-01, LQ-02, LQ-03, LQ-06 e LQ-07), refletindo o fracionamento hidrodinâmico durante o transporte e a ausência de dispersão provocada pelas e fitoclastos, ao contrário do que se observa nas amostras proximas do influxo fluvial com predomínio de dispersão provocada pelas correntes e fitoclastos. O registro de algas, principalmente Botryococcus braunii Kützig 1849, indica que o mecanismo de suspensão gradacional associado à queda na quantidade de MOA favorece a preservação e o acúmulo destas algas.

As diferentes palinofácies identificadas nos sedimentos de fundo da Lagoa dos Quadros apresentam variações na distribuição dos quatro grupos de componentes da matéria orgânica particulada, e são influenciadas, principalmente, pelas condições hidrodinâmicas e pelos processos deposicionais.

A palinofácies A, cuja principal característica é a distribuição praticamente equivalente dos quatro grupos de matéria orgânica particulada, está relacionada ao fundo arenoso-síltico e ao proces- so deposicional em suspensão gradacional, no qual há influência da corrente de fundo, que remove as partículas de sedimento para o alto, provocando movimentação na pluma de suspensão.

As palinofácies $\mathrm{B}$ e $\mathrm{C}$, identificadas nas proximidades do influxo fluvial, diferem entre si no conteúdo de MOA, que predomina na palinofácies $\mathrm{C}$. A maior concentração de MOA na amostra LQ-05 está diretamente relacionada à granulometria silte e condições de deposição em baixa energia pelo processo de suspensão em águas calmas. Na amostra LQ-10 de granulometria areia, o predomínio de MOA pode ser atribuído ser resultado da associação com a fração areia fina transportada por suspensão, componente característico da borda leste.

As amostras que caracterizam a palinofácies D foram depositadas sob controle de processos deposicionais com sedimentos distintos. No entanto, ambas amostras apresentam predomínio de MOA e fitoclastos opacos. Esta similaridade pode ser atribuída ao influxo do Rio Cornélios que, aparentemente, influencia diretamente as áreas das duas amostras. A distribuição significativa de MOA na amostra LQ-09, de granulometria areia, pode estar relacionada a ação do processo de suspensão que atua na deposição das areias finas nas fácies arenosas da margem leste.

Na palinofácies E, as amostras LQ-01 e LQ-03 apresentam maior similaridade quanto à distribuição dos grupos da matéria orgânica particulada, apesar de diferirem entre si quanto à granulometria. Estas amostras têm, em comum, a distância de aproximadamente $3 \mathrm{~km}$ da fonte fluvial do Rio Maquiné e do Arroio Sanga Funda. O processo deposicional de suspensão favoreceu, provavelmente, a deposição de MOA. Na amostra LQ06 a distribuição praticamente equivalente dos demais grupos de matéria orgânica particulada pode estar relacionada à maior distância do influxo fluvial e ao tempo em suspensão em ambiente de baixa energia e à maior profundidade do fundo.

As palinofácies recuperadas dos sedimentos de fundo da Lagoa dos Quadros mostram diversos padrões de distribuição relacionados, em parte, à fácies deltaicas (prodelta e frente deltaica) e ambiente lacustre (e.g., Boulter, 1994).

Boulter (1994) apresentou modelos de distribuição dos componentes orgânicos particulados em diferentes ambientes deposicionais. De acordo com este autor, a palinofácies dos lagos de água doce se caracteriza pelo predomínio de fitoclastos não opacos (palynowafers) e esporomorfos (grãos de pólen e esporos). A palinofácies de prodelta apresentaria o predomínio de MOA, fitoclastos não opacos e esporomorfos e as fácies de frente deltaica (em plataforma marinha) fitoclastos não opacos, cistos de dinoflagelados e esporomorfos.

As palinofácies relacionadas ao delta intra-lagunar do Rio Maquiné (palinofácies C e A e amostras LQ-03 e LQ-06) apresentam semelhança parcial ao modelo de Boulter (1994). A palinofácies $\mathrm{C}$, com predomínio fitoclastos opacos e não opacos, é semelhante a palinofácies de frente deltaica no que diz respeito ao predomínio de fitoclastos. As amostras LQ-03 e LQ-06 podem ser associadas a fácies de prodelta com contribuições equivalentes de fitoclastos não opacos e esporomorfos.

CONSIDERAÇÕES FINAIS Os resultados obtidos da análise de palinofácies nos sedimentos de fundo da Lagoa dos Quadros forneceram informações significativas a respeito das características e distribuição da matéria orgânica particulada e sua correlação com os processos deposicionais atuantes. Em relação à distribuição da matéria orgânica particulada nos sedimentos, foram confirmados alguns padrões conhecidos na análise de palinofácies, tais como:

As maiores concentrações de MOA nos sedimentos de fundo estão associadas a sedimentos finos de granulometria silte e silte-arenoso, onde prevalecem condições desóxicas-anóxicas favoráveis à preservação da matéria orgânica. 
Os fitoclastos não opacos estão relacionados à maior proximidade fluvial refletindo o transporte a partir das áreas de cobertura vegetal até o sítio deposicional.

Os fitoclastos opacos são mais abundantes em amostras de granulometria areia devido à alta capacidade de flutuação e resistência destas partículas a oxidação.

A análise de agrupamento modo- $R$ mostrou o grau de similaridade entre os componentes orgânicos, agrupados de acordo com sua equivalência hidrodinâmica e tendências de distribuição. A análise de agrupamento do modo- $Q$ reuniu as amostras em cinco agrupamentos: palinofácies A, B, C, D e E, de acordo com a abundância relativa dos componentes da matéria orgânica. A partir da correlação entre as variações dos percentuais dos componentes da matéria orgânica em cada amostra com o processo deposicional que controla a deposição dos sedimentos, foi possível estabelecer as seguintes inferências:

Palinofácies A: com equivalência entre os quatro grupos da matéria orgânica, está associada ao fundo areno-síltico e ao processo de deposição em suspensão gradacional.

Palinofácies B, com predomínio de fitoclastos opacos e Palinofácies $\mathrm{C}$, com predomínio de MOA e fitoclastos não opacos: relacionadas ao processo de suspensão e rolamento, com aumento na fração de fitoclastos, evidenciando a proximidade da fonte fluvial e o transporte por rolamento, e aumento de MOA sugerindo o transporte em suspensão.

Palinofácies D (predomínio de MOA e fitoclastos opacos): associada a processos de suspensão e rolamento com influência fluvial.

Palinofacies E (predomínio de MOA e palinomorfos): característica dos sedimentos finos e relacionada a processos deposicionais de suspensão uniforme e suspensão em águas calmas.

Dessa forma os resultados apresentados constituem significativa avaliação das variáveis que atuam na sedimentação da matéria orgânica e se inserem como importante parâmetro na interpretação de paleoambientes lacustres com influxo fluvial.

Agradecimentos À Estação de Piscicultura da Fundação Estadual de Pesquisa Agropecuária-FEPAGRO e aos pesquisadores Gil Ortiz e Paulo Chagas pelo apoio logístico no trabalho de campo. Ao Laboratório de Palinologia da Universidade Luterana do Brasil e, em especial, a Paulo Cesar Pereira das Neves e a Emerson Prochnow, por terem disponibilizado os recursos para a preparação das amostras. A primeira autora agradece ao Conselho Nacional de Desenvolvimento Científico e Tecnológico-CNPq pela concessão de bolsa. Este trabalho é dedicado a Marleni Marques Toigo (in memoriam) em reconhecimento a sua contribuição na produção científica e transmissão de conhecimentos às novas gerações.

\section{Referências}

Boulter M.C. 1994. An approach to a Standard terminology for palynodebris In: A. Traverse (ed.) Sedimentation of Organic Particles. Cambridge University Press, Cambridge, p.199-216.

Combaz A. 1964. Les palynofacies. Rev. Micropal., 7:205-218.

Courtinat B., Piriou S., Rio M. 2003. Phytoclasts in palynofacies definition: the example of Rhaetian sedimentary organic matter in SE France. Rev. Micropal., 46:11-21.

Cwik M.R. 1999. Aspectos fisicos e sedimentológicos da Lagoa dos Quadros - litoral norte do Rio Grande do Sul. Dissertação de Mestrado, Instituto de Geociências, Universidade Federal do Rio Grande do Sul, Porto Alegre, $180 \mathrm{p}$.

Ghignone J.I. 1960. Reconhecimento gravimétrico na Bacia de Pelotas. Bol. Téc. Pet., 3(2):73-79.

Mendonça Filho J.G. 1999. Aplicação de estudos de palinofácies e fácies orgânica em rochas do Paleozóico da Bacia do Paraná, Sul do Brasil. Tese de Doutoramento, Instituto de Geociências, Universidade Federal do Rio Grande do Sul, Porto Alegre, 338 p.

Mendonça Filho J.G., Menezes T.R., Iemma M.B. 2001b. Caracterização organocomposicional de sedimentos holocênicos da margem continental do Atlântico Sul (Brasil). In: ABEQUA, Congr. Assoc. Bras. Est. Quat., 8, Anais, p 234.

Mendonça Filho J.G., Menezes T.R., Iemma M.B., Oliveira A.E. 2003. Caracterização organocomposicional dos sedimentos de fundo da Baía de Guanabara-RJ. In: ABEQUA, Congr. Plan. Gest. Zon. Cost. Países Expr. Port., 2 \& Congr. Assoc. Brás. Est. Quat., 9 \& Congr. Quat. Países Ling. Ibér, 2. Anais, CR-Rom.

Mendonça Filho J.G., Peralba M.C.R., Elias W.O., Marques-Toigo M., Jaffé R., Menezes T.R. \& Iemma M.B. 2001a. Caracterização da composição orgânica particulada e análise da fração orgânica mole- cular de sedimentos holocênicos do vale do Rio Maquiné, Brasil. In: ABEQUA, Congr. Assoc. Bras. Est. Quat., 8, Anais, p. 76.

Menezes T.R. \& Mendonça Filho J.G. 2004. Aplicação de fácies orgânica na análise paleoceanográfica do talude continental superior recente da Bacia de Campos. Rev. Bras. Paleont., 7(2):177-188.

Tomazelli L.J. \& Villwock J.A. 2000. O Cenozóico Costeiro do Rio Grande do Sul. In: M. Holz \& L.F. de Ros (eds.) Geologia do Rio Grande do Sul. Ed. CIGO/UFRGS, Porto Alegre, p. 375-406.

Traverse A. 1994. Sedimentation of palynomorphs and palynodebris: an introduction. In: A. Traverse (ed.) Sedimentation of Organic Particles. Cambridge University Press, Cambridge, p. 1-8.

Trigüis J. A. \& Araújo L.M. 2001. Aplicação da petrografia orgânica na caracterização dos tratos de sistemas. In: H.J.P.S. Ribeiro (ed.) Estratigrafia de Seqüencias Fundamentos e Aplicações. São Leopoldo, Ed. Unisinos, p. 261-302.

Tyson R.V. 1993. Palynofacies analysis. In: D.G. Jenkins (ed.) Applied Micropaleontology. Kluver, Dondrecht, p.153-191.

Tyson R.V. 1995. Sedimentary Organic Matter: Organic facies and palynofacies analysis. Chapman \& Hall, London, $615 \mathrm{p}$.

Valentin J.L. 2000. Ecologia Numérica: uma introdução à análise multivariada de dados ecológicos. Interciência, Rio de Janeiro, 117 p.

Villwock J.A. 1984. Geology of the coastal province of Rio Grande do Sul, southern Brazil: a synthesis. Pesquisas, 16:5-49.

Villwock J.A. \& Tomazelli L.J. 1995. Geologia Costeira do Rio Grande do Sul. Porto Alegre, CECO/UFRGS, Notas Técnicas 8, $45 \mathrm{p}$.

Manuscrito A1535

Aprovado em 30 de outubro de 2006 